Section Editor

Mitchell S.V. Elkind,

MD, MS

Cory Edwards, MD

Enrique C. Leira, MD, MS

Pedro Gonzalez-Alegre, $\mathrm{MD}, \mathrm{PhD}$

Correspondence to

Dr. Gonzalez-Alegre:

pedro.gonzalez-alegre@

uphs.upenn.edu
Residency Training:

\section{A failed lumbar puncture is more about obesity than lack of ability}

\section{ABSTRACT}

Objective: To identify factors influencing the success of lumbar puncture (LP) performed by neurology residents in an outpatient clinic.

Background: There is a need to understand the specific influence of patient or operator characteristics in LP performance in order to identify situations at high risk for failure that could benefit from compensatory interventions.

Methods: We performed a retrospective analysis of all consecutive patients who underwent elective LP in the Neurology Clinic at the University of lowa between 2009 and 2012. We recorded demographic, anthropometric, and clinical information, and the level of training of the resident performing the procedure. Outcomes measure was unsuccessful LP, defined as no quantifiable CSF. This study was previously approved by the University of lowa institutional review board.

Results: A total of 328 patients (59\% women) were included. Men were significantly older than women, and the indication of the procedure differed by sex. Headache or possible multiple sclerosis were more common indications in women than in men. Nineteen percent of the LPs were unsuccessful. We found a strong correlation between patient body mass index (BMI) and unsuccessful outcome $(p<0.0001)$. Age of the patient and level of training of the operator did not predict unsuccessful LP.

Conclusions: Patient BMI is the key factor that determines an unsuccessful LP by neurology residents in an outpatient setting, an association that might be applicable to different clinical settings. The high failure rate in patients with $\mathrm{BMI}>35$ suggests that implementing compensatory interventions such as the use of imaging guidance might be cost-effective and better tolerated by these patients. Neurology ${ }^{\circledR}$ 2015;84:e69-e72

GLOSSARY

BMI = body mass index; $\mathbf{L P}=$ lumbar puncture.

Lumbar puncture (LP) is a procedure commonly performed during the evaluation of multiple conditions that affect the nervous system. As stated by Karen Roos, ${ }^{1}$ the LP "is one of the more difficult procedures in medicine because success is not only dependent on the skill of the physician but also the size, anatomy, and comfort of the patient." Changes in physician and patient characteristics seen in recent decades have the potential to negatively influence the successful completion of this procedure.

Due to advances in noninvasive testing, the number of LPs being performed has probably decreased. As a consequence, neurology residents perform fewer LPs than decades ago. According to the Centers for Disease Control and Prevention, 34.9\% of US adults are obese (www.cdc. gov/obesity/data/adult.html), with a dramatic increase in obesity rates between 1990 and 2010. As a consequence of these changes, it is more likely to encounter obese or older patients with degenerative disease of the spine. Understanding which of these factors has a greater influence the outcome of the LP could provide a rational basis for designing educational programs or compensatory interventions aiming to improve the rate of successful LPs.

From the Department of Neurology, University of Iowa Carver College of Medicine, Iowa City.

Go to Neurology.org for full disclosures. Funding information and disclosures deemed relevant by the authors, if any, are provided at the end of the article. 


\begin{tabular}{|c|c|c|c|}
\hline \multirow[t]{2}{*}{ Table 1} & atures of the & & \multirow[b]{2}{*}{ Total } \\
\hline & Women & Men & \\
\hline No. & 190 & 136 & 326 \\
\hline Age, $y$, mean \pm SEM ${ }^{a}$ & $42.9 \pm 1.1$ & $51.8 \pm 1.5$ & $44.7 \pm 0.8$ \\
\hline $\mathrm{BMI}$, mean $\pm \mathrm{SEM}^{\mathrm{b}}$ & $26.9 \pm 0.5$ & $30.2 \pm 6.6$ & $29.4 \pm 0.4$ \\
\hline \multicolumn{4}{|l|}{ Indication (\%) } \\
\hline Headache & $44(23)$ & $14(10)$ & $58(18)$ \\
\hline Multiple sclerosis & $96(50)$ & $36(26)$ & $132(40)$ \\
\hline Neuropathy & $13(7)$ & $32(24)$ & 45 (14) \\
\hline Other & $37(20)$ & $54(40)$ & $91(28)$ \\
\hline
\end{tabular}

Body mass index (BMI) not available in 10 subjects.

a $p<0.0001$.

${ }^{\mathrm{b}} \mathrm{p}=0.09$.

The aim of this study is to identify which patient or operator characteristics determine the unsuccessful completion of LP during a residency program. The hypotheses were that resident inexperience, high body mass index (BMI), and advanced patient age correlated with unsuccessful LP.

METHODS We performed a retrospective study at University of Iowa HealthCare, an academic tertiary care system. We used our Electronic Medical Record and billing system to identify all consecutive patients who underwent LP in the Outpatient Neurology Clinic from 2009 to 2012. Variables collected included age, sex, weight, BMI, indication for the LP, and outcome (whether CSF was obtained or not). We also recorded the characteristics of the operator: resident vs postresidency and postgraduate year of training (PGY). Statistical analysis of the data was performed using Prism (GraphPad Software, La Jolla, CA) statistical software. $\chi^{2}$ tests or Fisher exact tests were performed to determine which categories were significantly different from one another, and $t$ test was used to compare continuous variables. Analysis of variance was used when comparing multiple groups. $p$ Values $\leq 0.05$ were considered significant.

RESULTS A total of 328 patients were identified and 2 were excluded as data about the outcome of the LP were missing. Basic demographic, clinical, and anthropomorphic information on the 326 patients included is shown in table 1 . The BMI was not available for 10 subjects. Those were excluded from the BMI analysis. Men and women undergoing LP differed on the indication for the procedure and age (table 1).

As shown in table 2, over $80 \%$ of attempted LPs were successfully completed. We first asked whether age, sex, and patient BMI, or the indication for the procedure, influenced the outcome of the LP. Only BMI was significantly higher in subjects with a failed LP (table 2). Table 2 also shows a correlation between patient BMI and the probability of an unsuccessful
LP with close to half of failed procedures in patients with a BMI $>35$. Finally, we found that those undergoing the LP for the evaluation of headache had a higher BMI than patients with other indications (table 2).

Next, we evaluated the influence of the level of training of the physician performing the LP on its outcome. Due to the organization of our clinic and training program, most of the LPs were performed by residents at the PGY3 level (table 3). Level of training did not influence the outcome. Interestingly, there was nonsignificant trend towards higher failure rate with more advanced training, a paradoxical association confounded by the fact that the more senior physicians were performing the procedure on higher weight individuals (table 3).

DISCUSSION There is a subjective perception among neurologists that the proportion of failed LPs has increased in the last decade or two. Among the several factors that have been proposed to explain this possibility are a reduction in the number of LPs performed by neurologists and trainees, the aging of the population as age-related degenerative lumbar disease could make the LP more challenging, and the obesity epidemic. In patients with high BMI, identification of the appropriate landmarks can be difficult. Our study strongly suggests that the patient's BMI, and not the level of training of the operator, is the most important predictor of successful completion of the LP. Whereas the association between a failed LP and increased patient BMI is a popular belief among neurologists and can be inferred by anecdotal reports, it has been strongly corroborated and quantified by this study. The dose effect between BMI and probability of unsuccessful LP supports the causality of this variable. While intuitive, we believe that confirming these findings is important. 


\section{Table 2 Correlation of patient characteristics with the indication and outcome of the lumbar puncture}

$\begin{array}{ll}\text { Characteristics } & \text { Values } \\ \text { Success by sex, \%a } & \\ \text { Women } & 79 \\ \text { Men } & 86 \\ \text { All } & 81 \\ \text { Success by indication, \% } & \\ \text { Headache } & 74 \\ \text { Multiple sclerosis } & 82 \\ \text { Neuropathy } & 84 \\ \text { Other } & 85\end{array}$

Success by age group, $y, \%^{a}$

$<30$

85

31-40

75

41-50

82

51-60

87

61-70

$71-80$

$>80$

Age, $y$, mean $\pm S^{2} M^{a}$

Successful

$46.5 \pm 1.02$

Failed

$47.7 \pm 2.13$

Success by BMI group

$\leq 20$

94

$>20-25$

$>25-30$

$>30-35$

$>35^{\mathrm{b}}$

BMI by indication, mean \pm SEM

Headache ${ }^{\text {b }}$

$34.3 \pm 1$

Multiple sclerosis

$28.9 \pm 0.6$

Neuropathy

$29.2 \pm 0.8$

Other

$27.8 \pm 0.5$

$\mathrm{BMI}$, mean $\pm \mathrm{SEM}^{\mathrm{C}}$

Successful

$28.5 \pm 0.37$

Failed

$33.9 \pm 1$

Abbreviation: $\mathrm{BMI}=$ body mass index.

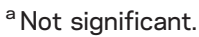

${ }^{\mathrm{b}} p<0.0001$ (analysis of variance).

${ }^{c} p<0.0001$ (unpaired, 2-tailed $t$ test).

Our findings are consistent with previous studies suggesting an inverse relationship between BMI and unsuccessful LP. ${ }^{2}$ A study conducted by Stiffler et al. ${ }^{3}$ addressed the relationship between BMI and ability to identify landmarks. Successful identification of landmarks by palpation was successful in all subjects with normal BMI but only in $74 \%$ of obese patients. In addition, Halpenny et al. ${ }^{4}$ showed that the standard 9-cm spinal needle may not reach the subarachnoid space in all individuals, as $13.8 \%$ of individuals had a longer than $9 \mathrm{~cm}$ skin to subarachnoid space distance. We hypothesize that the use of longer needles and implementation of methods to assist in landmark identification would translate into a higher success rate in patients with BMI $>35$.

All of our failed procedures underwent a fluoroscopy-guided LP, which was successful in $100 \%$. In addition to increased patient discomfort and financial burden caused by multiple clinic visits, this leads to added costs of performing 2 separate procedures. At our institution, the bill for a fluoroscopicguided LP is about a third higher than for a bedside landmark LP. Besides fluoroscopy, there are other alternatives to assist LP that do not involve ionizing radiation and can be performed in the clinic, such as ultrasound (US). ${ }^{5,6}$ Substantial evidence supports the use of US guidance to perform LPs. In the study mentioned earlier linking BMI with landmark identification, US guidance allowed their identification in all obese patients, ${ }^{3}$ and others showed its benefit when performing LPs in different settings. ${ }^{7-9}$ The added costs of fluoroscopy and US guidance over the standard procedure seem comparable. ${ }^{10}$ The benefits, risks, and cost of stratifying morbidly obese patients to an initial USassisted LP in the clinic should be prospectively evaluated. The LP is one of the procedural domains incorporated into the Next Accreditation System recently released by the Accreditation Council for Graduate Medical Education for neurology training. If effective, competency in the use of US guidance for LPs could be incorporated as a milestone for this domain.

We were surprised to find little influence of resident experience on the success of the LP. Our data suggest that residents acquire LP competency early on during training, as successful completion is not influenced by level of training. Because simulationbased learning of the LP has been shown to be effective for medical residents, ${ }^{11}$ programs should perhaps capitalize on this steep learning curve and incorporate the use of LP simulators that mimic obese patients early during training.

There are several limitations to this study. First, this is a retrospective review and, therefore, subject to the potential bias of such experimental design. Nevertheless, the variables of interest for this study were objective and accurate with very small rate of missing data. The inverse relationship found between the patient BMI and rate of success is robust, dosedependent, and unlikely a result of the limitations of the experimental design. A more likely source of bias is found in the operator data. Due to the organization of our clinic and training programs, most neurology residents performing the procedure were at the 


\begin{tabular}{|llll|}
\hline Table 3 & \multicolumn{4}{l}{ Level of training and outcome of the lumbar puncture } \\
\hline Level of training & \% LPs & \% Success & Patient BMI, mean \pm SEM $^{\text {b }}$ \\
PGY1-2 & 11 & 85.7 & $27.7 \pm 1.2$ \\
PGY3 & 76 & 82.3 & $29.7 \pm 0.4$ \\
PGY4 & 8 & 79.2 & $29.3 \pm 1$ \\
Postresidency & 5 & 68.4 & $31.8 \pm 1.4$ \\
\hline
\end{tabular}

Abbreviations: $\mathrm{BMI}=$ body mass index; $\mathrm{LP}=$ lumbar puncture; $\mathrm{PGY}=$ postgraduate year. ${ }^{a} p=0.3$.

${ }^{b} p=0.2$.

\section{STUDY FUNDING}

No targeted funding reported.

\section{DISCLOSURE}

The authors report no disclosures relevant to the manuscript. Go to Neurology.org for full disclosures.

\section{REFERENCES}

1. Roos KL. Lumbar puncture. Semin Neurol 2003;23:105114.

2. Boddu SR, Corey A, Peterson R, et al. Fluoroscopicguided lumbar puncture: fluoroscopic time and implications of body mass index: a baseline study. AJNR Am J Neuroradiol 2014;35:1475-1480.

PGY3 level, which limits our ability to compare the ability of different class of residents. Furthermore, the resident performing the LP is supervised by an attending. If the resident is unsuccessful, whether the supervising physician attempts the procedure or the resident is referred directly to image-guided procedure is left to the discretion of the attending. Thus, when facing a morbidly obese patient, the attending may opt to directly refer the patient for fluoroscopy guidance, predicting a low likelihood of success. We recognize that this is a potential source of selection bias, and therefore we need prospective studies to determine the potential influence of seniority on success when performing a LP.

We showed that the patient BMI inversely correlates with the probability of a successful LP in the outpatient setting. Furthermore, this higher failure rate is mostly found in patients with BMI $>35$. Given that the rate of obesity continues to rise, educational programs and complementary interventions aimed at improving outcomes in this population should be implemented.

\section{AUTHOR CONTRIBUTIONS}

Dr. Edwards participated in the study design, data collection, analysis and interpretation, and drafted the first version of the manuscript. Dr. Leira participated in the study design, data analysis (including statistical analysis) and interpretation, and revised the manuscript for content. Dr. Gonzalez-Alegre participated in the study design, data analysis (including statistical analysis) and interpretation, and revised the manuscript for content.
3. Stiffler KA, Jwayyed S, Wilber ST, Robinson A. The use of ultrasound to identify pertinent landmarks for lumbar puncture. Am J Emerg Med 2007;25:331334.

4. Halpenny D, O'Sullivan K, Burke JP, Torreggiani WC. Does obesity preclude lumbar puncture with a standard spinal needle? The use of computed tomography to measure the skin to lumbar subarachnoid space distance in the general hospital population. Eur Radiol 2013;23:31913196.

5. Peterson MA, Abele J. Bedside ultrasound for difficult lumbar puncture. J Emerg Med 2005;28:197-200.

6. Rizzoli P. Taking the sting out of lumbar puncture. BMJ 2013;346:f1734.

7. Hayes J, Borges B, Armstrong D, Srinivasan I. Accuracy of manual palpation vs ultrasound for identifying the L3-L4 intervertebral space level in children. Paediatr Anaesth 2014;24:510-515.

8. Mofidi M, Mohammadi M, Saidi H, et al. Ultrasound guided lumbar puncture in emergency department: time saving and less complications. J Res Med Sci 2013;18: 303-307.

9. Nomura JT, Leech SJ, Shenbagamurthi S, et al. A randomized controlled trial of ultrasound-assisted lumbar puncture. J Ultrasound Med 2007;26:1341-1348.

10. Brook AD, Burns J, Dauer E, Schoendfeld AH, Miller TS. Comparison of CT and fluoroscopic guidance for lumbar puncture in an obese population with prior failed unguided attempt. J Neurointerv Surg 2014;6: 323-327.

11. Barsuk JH, Cohen ER, Caprio T, et al. Simulation-based education with mastery learning improves residents' lumbar puncture skills. Neurology 2012;79:132-137. 


\title{
Neurology
}

\author{
Residency Training: A failed lumbar puncture is more about obesity than lack of \\ ability \\ Cory Edwards, Enrique C. Leira and Pedro Gonzalez-Alegre \\ Neurology 2015;84;e69-e72 \\ DOI 10.1212/WNL.0000000000001335
}

This information is current as of March 9, 2015

\section{Updated Information \& Services}

References

Citations

Subspecialty Collections

Permissions \& Licensing

Reprints including high resolution figures, can be found at: http://n.neurology.org/content/84/10/e69.full

This article cites 11 articles, 5 of which you can access for free at: http://n.neurology.org/content/84/10/e69.full\#ref-list-1

This article has been cited by 2 HighWire-hosted articles: http://n.neurology.org/content/84/10/e69.full\#\#otherarticles

This article, along with others on similar topics, appears in the following collection(s):

\section{All Education}

http://n.neurology.org/cgi/collection/all_education

All Headache

http://n.neurology.org/cgi/collection/all_headache

Cerebrospinal Fluid

http://n.neurology.org/cgi/collection/cerebrospinal_fluid

Diagnostic test assessment

http://n.neurology.org/cgi/collection/diagnostic_test_assessment_

Information about reproducing this article in parts (figures,tables) or in its entirety can be found online at:

http://www.neurology.org/about/about_the_journal\#permissions

Information about ordering reprints can be found online:

http://n.neurology.org/subscribers/advertise

Neurology ${ }^{\circledR}$ is the official journal of the American Academy of Neurology. Published continuously since 1951, it is now a weekly with 48 issues per year. Copyright () 2015 American Academy of Neurology. All rights reserved. Print ISSN: 0028-3878. Online ISSN: 1526-632X.

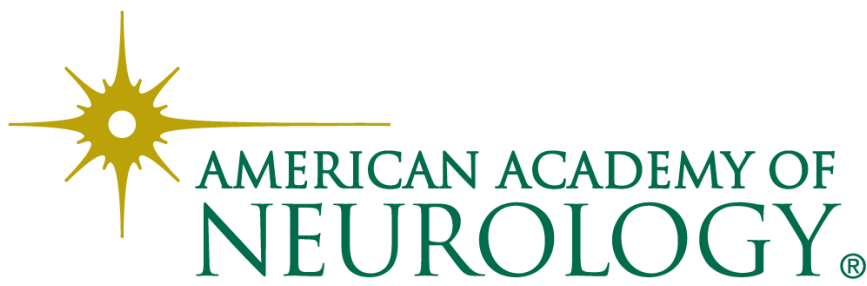

